Revista Geográfica Digital. IGUNNE. Facultad de Humanidades. UNNE. Año 14. № 27.

Enero - Junio 2017. ISSN 1668-5180 Resistencia, Chaco

\title{
ÁRBOLES NATIVOS DE MONTAÑA EN PAISAJES CORDILLERANOS: EL CASO DE LAS PULPICAS DE TULAHUENCITO.
}

\author{
Eduardo Antonio Jaime Muñoz. \\ Magister en Desarrollo Regional y Medio \\ Ambiente. \\ Universidad de Valparaíso. \\ E-mail: ejaime18@gmail.com
}

\section{RESUMEN.}

Se presenta un estudio de caso relacionado con los árboles nativos de montaña, se trabaja con las pulpicas de Tulahuencito, estos árboles se encuentran en el sector montañoso cercano a la localidad de La Tranquita, comuna de Monte Patria, Región de Coquimbo.

La metodología a emplear es análisis bibliográfico, elaboración de cartografía, se establecieron mediciones utilizando cuadrante de $5 \times 5$ metros, para evaluar la cantidad de plantas que existe en la parcela, la edad del vegetal encontrado, la altura y el ancho de los individuos y la presencia de nuevas plántulas debajo de las pulpicas. También se evaluó el suelo donde se encuentran estos árboles de montaña y el estado fenológico de los vegetales. La idea es contar con un registro que permita la comunidad del sector cuidar y conservar estos árboles nativos. El objetivo de este trabajo es evaluar el espacio geográfico y las características naturales de las pulpicas, considerando sus potencialidades y amenazas. Los resultados serán un aporte a los pobladores del sector para conservar y promover el uso responsable de estos árboles de montaña.

Palabras claves: árboles, pulpica, flora nativa, montaña, comunidad y biodiversidad.

\section{SUMMARY.}

We present a case study related to the native mountainous trees, we work with the pulpicas of Tulahuencito, these trees are in the mountainous sector near the locality of La Tranquita, commune of Monte Patria, Region of Coquimbo.

The methodology to be used is bibliographic analysis, mapping, measurements were established using a $5 \times 5$ meter quadrant, to evaluate the number of plants in the plot, the age of the plant found, the height and width of the individuals and The presence of new seedlings below the pulpicas. We also evaluated the soil where these mountain trees and the phenological state of the plants are located. The idea is to have a registry that allows the community of the sector to care for and preserve these native trees. The objective of this work is to evaluate the geographical space and the natural characteristics of the pulpicas, considering their potentialities and threats. The results of this study will be a contribution to the community in the area. The results of this study will be a contribution to the people of the sector to conserve and promote the responsible use of these mountain trees.

Key words: trees, pulpica, native flora, mountain, community and biodiversity

\footnotetext{
Publicado en formato digital: Mgtr Eduardo Antonio Jaime Muñoz. ÁRBOLES NATIVOS DE MONTAÑA EN PAISAJES CORDILLERANOS: EL CASO DE LAS PULPICAS DE TULAHUENCITO. Revista Geográfica Digital. IGUNNE. Facultad de Humanidades. UNNE. Año 14. № 27. Enero - Junio 2017. ISSN 1668-5180 Resistencia, Chaco.

En: http://hum.unne.edu.ar/revistas/geoweb/default.htm
} 
Revista Geográfica Digital. IGUNNE. Facultad de Humanidades. UNNE. Año 14. № 27.

Enero - Junio 2017. ISSN 1668-5180 Resistencia, Chaco

\section{INTRODUCCIÓN.}

La importancia de conocer y comprender los hábitats naturales de las plantas nativas, es un aporte al desarrollo de las comunidades que viven insertas en ecosistemas de gran riqueza pero vulnerables a ser degradados por las actividades humanas. En este contexto la cuenca de Tulahuencito es un lugar milenario, para la historia natural de la Región de Coquimbo, ubicada en la precordillera andina en la comuna de Monte Patria posee una vegetación nativa de gran importancia para la conservación de la biodiversidad (Jaime, 2014).

Una diversidad de plantas acompaña la geografía escabrosa de Tulahuencito, sobre los faldeos de las laderas y en el fondo de las quebradas asoman montes verdes donde se distinguen arbustivos espinosos, cactáceas, enredaderas y un tipo de árbol que crece en los cordones montañosos del área de estudio, conocido por los lugareños como pulpica estos árboles frondosos, adoran y enriquecen el paisaje de la cordillera andina.

Los árboles de montaña habitan la zona de vegetación típica altoandina. Juegan un papel importante en el ecosistema chileno. Dentro de estas especies vegetales se encuentra la Kageneckia angustifolia D.Don. Fam Rosáceas "El Olivillo" o "Pulpica" alcanza los 3000 m.s.n.m en la cordillera de las provincias centrales (Hoffmann, et al, 1998).

La Pulpica es un árbol que crece en el ecosistema natural de Tulahuencito, las poblaciones del vegetal han sido diezmadas producto de la corta para leña y carbón actividad muy común en las zonas rurales, donde el trabajo escasea y la gente para poder coser sus alimentos, recolecta la leña de esta especie nativa.

Según Jaime, 2013, el árbol la Kageneckia angustifolia: Pulpica es endémica de Chile y ha sido diagnosticada por el libro Rojo de los sitios prioritarios para su conservación en la Región de Coquimbo en categoría $(E P)=$ En Peligro de Extinción. La Planta en la zona de Tulahuencito habita preferentemente laderas de exposición sur y crece sobre cantos rodados que se ubican en las altas montañas del Limarí.

La planta siempreverde, de hasta $10 \mathrm{~m}$ de altura por 4 de diámetro, de copa globosa y tronco delgado, de unos $50 \mathrm{~cm}$ de diámetro. Hojas glabras, coriáceas, simples alternas, de borde aserrado y de color verde claro, de $9 \times 1 \mathrm{~cm}$ (Riedemann et al, 2008). Estas características naturales de la planta, dan vida a un pequeño sector donde predominan las pulpicas.

En otoño e invierno la planta aprovecha las escasas precipitaciones que caen en estas zonas semiáridas, para guardar reservas energéticas y ser utilizadas en la temporada de primavera y verano, estaciones donde los árboles renuevan su follaje y sus flores llaman a los polinizadores. Sin embargo, los periodos de sequias y el sobrepastoreo caprino han degradado el paisaje natural donde habitan estas plantas.

Según los antecedentes planteados la pulpica es un árbol de montaña inserta en el paisaje de Tulahuencito que requiere ser estudiada, por esta razón surge la siguiente

Publicado en formato digital: Mgtr Eduardo Antonio Jaime Muñoz. ÁRBOLES NATIVOS DE MONTAÑA EN PAISAJES CORDILLERANOS: EL CASO DE LAS PULPICAS DE TULAHUENCITO. Revista Geográfica Digital. IGUNNE. Facultad de Humanidades. UNNE. Año 14. № 27. Enero - Junio 2017. ISSN 1668-5180 Resistencia, Chaco.

En: http://hum.unne.edu.ar/revistas/geoweb/default.htm 
pregunta de investigación ¿Cuáles son los antecedentes que permiten un mayor compresión del habitat natural de la pulpica árbol de montaña en la zona de Tulahuencito.

\section{METODOS.}

Para el análisis de información en relación a los árboles de montaña se revisó a (Hoffmann et al, 1998), (Riedemann, et al, 2008), (Peñaloza et al, 2001), (Inventario Nacional del Ministerio de Medio Ambiente, 2016). (Squeo et al, 2001) y (Luebert y Pliscoff, 2006).

La elaboración de la cartografía de la zona estudiada se hizo con la ayuda del programa (Google Earth, 2016) y (ArMap 10.1), donde se identificaron lugares comunes, como el sector "El pulpical"; nombre que los cabreros asignan a la población de pulpicas en Tulahuencito.

Los cuadrantes empleados para medir la cantidad de individuos se hicieron con la ayuda de (Samo, et al, 2008). La evaluación de las plantas nativas se hizo utilizando una cinta métrica, lupas y una hoja de muestreo para el registro de los datos obtenidos en las mediciones en terreno. Los datos obtenidos de las mediciones realizadas en los trabajos de campo fueron procesados con la ayuda de programas computacionales.

\section{ESQUEMA DE LOS PASOS METODOLOGICOS.}

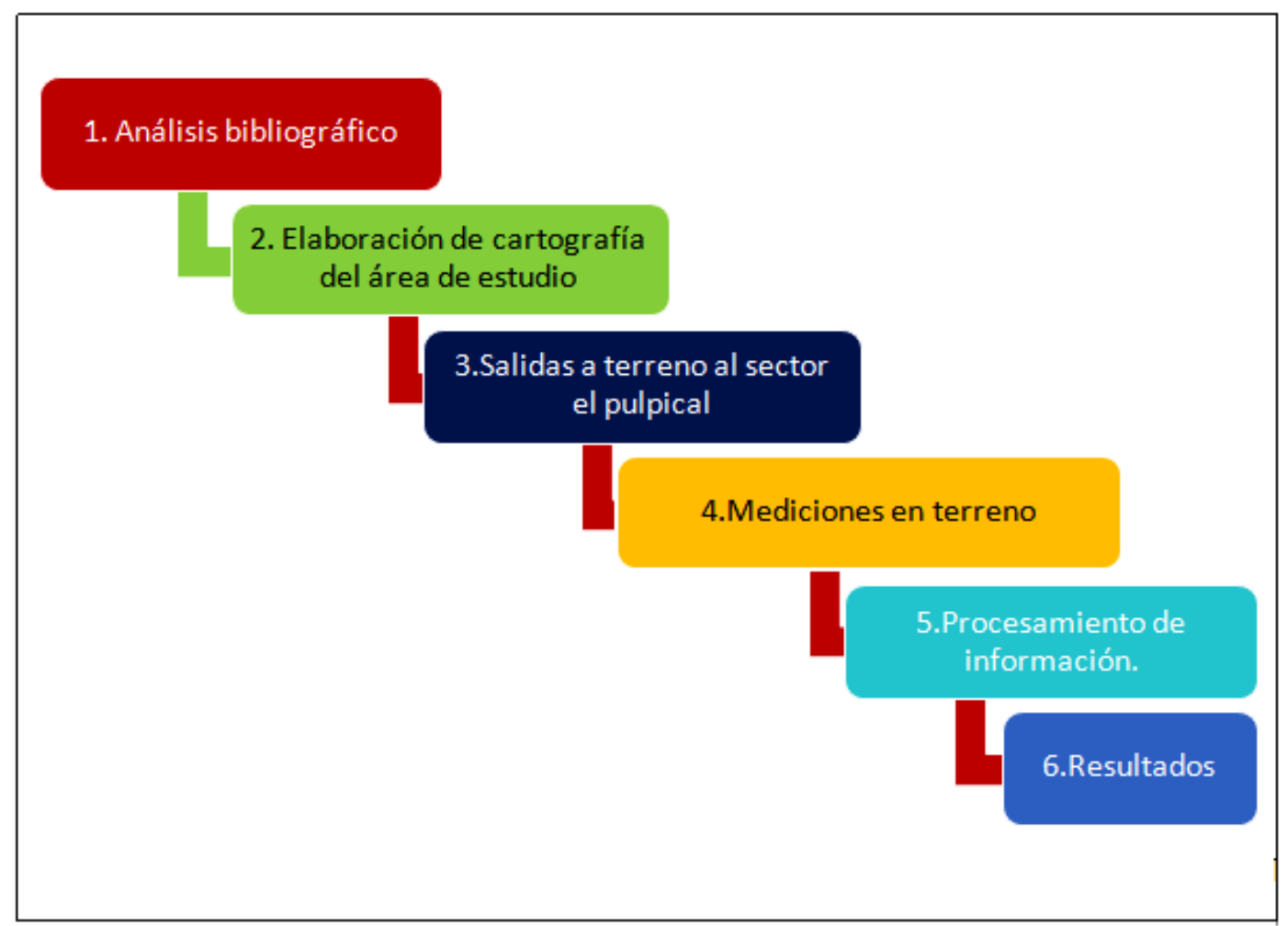

Cuadro 1: Pasos metodológicos, para la evaluación de árboles de montaña el caso de las pulpicas de Tulahuencito, comuna de Monte Patria, Región de Coquimbo. (Elaboración propia, 2017).

Publicado en formato digital: Mgtr Eduardo Antonio Jaime Muñoz. ÁRBOLES NATIVOS DE MONTAÑA EN PAISAJES CORDILLERANOS: EL CASO DE LAS PULPICAS DE TULAHUENCITO. Revista Geográfica Digital. IGUNNE. Facultad de Humanidades. UNNE. Año 14. № 27. Enero - Junio 2017. ISSN 1668-5180 Resistencia, Chaco.

En: http://hum.unne.edu.ar/revistas/geoweb/default.htm 


\section{AREA DE ESTUDIO.}

Las pulpicas de Tulahuencito, se ubican geográficamente en las siguientes coordenadas geográficas $\left(30^{\circ} 55^{\prime} 27.85 " S\right.$ y $\left.70^{\circ} 37^{\prime} 6.21^{\prime \prime O}\right)$ el Norte limita con las cumbres del cerro "Fajas blancas" el Sur con las cumbres del "cerro de Tulahuén".

La topografía de la zona se encuentra conformada accidentes geográficos en el centro de la ladera denominada por los cabreros como "el pulpical" se ubica una quebrada que contiene gran cantidad de material rocoso conocido como cantos rodados. En el sector Oeste de la ladera se observan una pequeña planicie que parte de la población de pulpicas. En el lado Este de la ladera el relieve tiende a ser más rocoso y con una mayor pendiente.

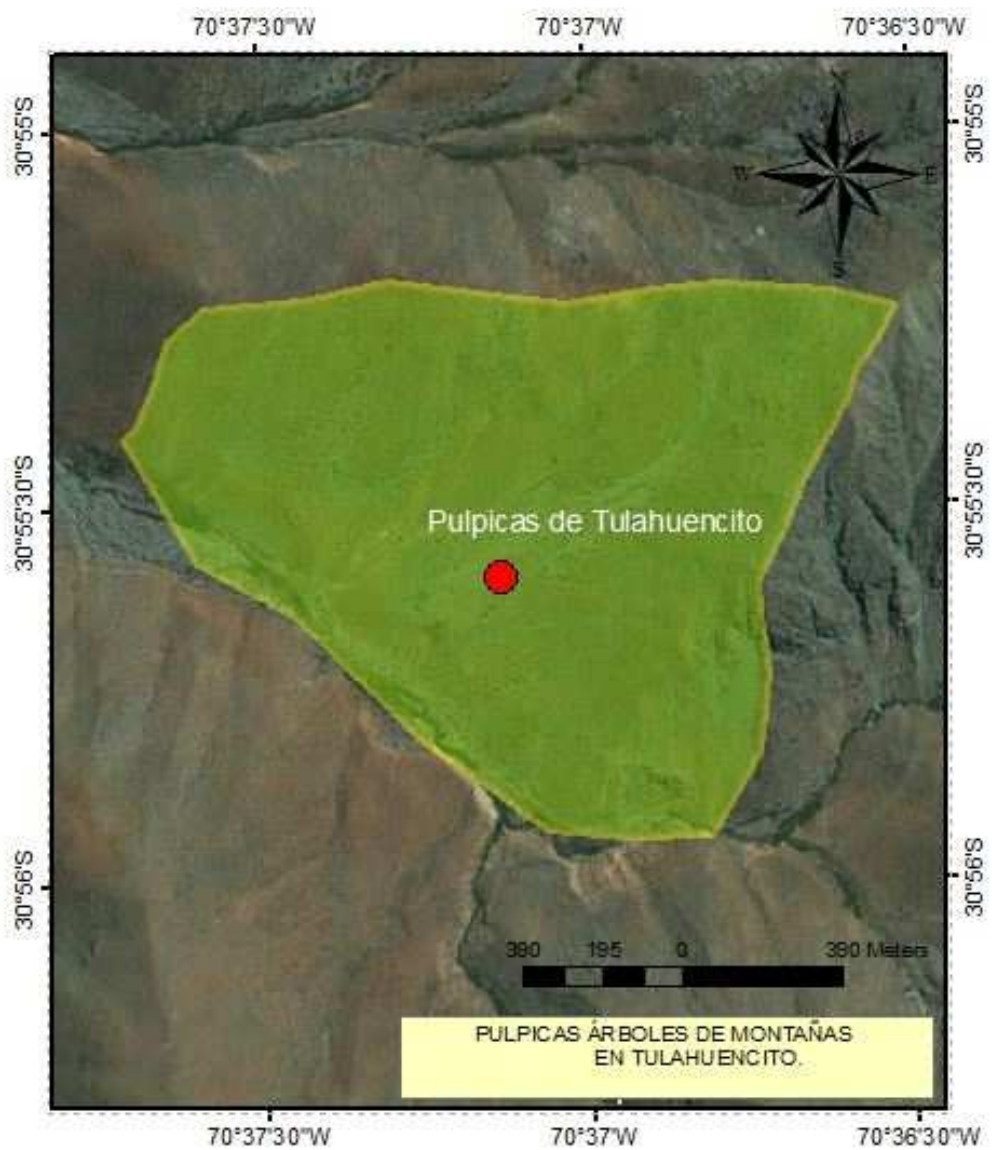

Figura 1: El mapa de las pulpicas, árboles de montañas en la Cuenca de Tulahuencito, comuna de Monte Patria, Región de Coquimbo, (Google Earth, 2017).

La población de pulpicas se encuentra cercana a la localidad de La Tranquita, el poblado posee una población de 77 personas (INE, 2005). Las personas de la comunidad se

Publicado en formato digital: Mgtr Eduardo Antonio Jaime Muñoz. ÁRBOLES NATIVOS DE MONTAÑA EN PAISAJES CORDILLERANOS: EL CASO DE LAS PULPICAS DE TULAHUENCITO. Revista Geográfica Digital. IGUNNE. Facultad de Humanidades. UNNE. Año 14. № 27. Enero - Junio 2017. ISSN 1668-5180 Resistencia, Chaco.

En: http://hum.unne.edu.ar/revistas/geoweb/default.htm 
dedican principalmente a la actividad ganadera y a labores como el cuidado de sus huertos, donde cultiva frutos secos y la siembra los porotos y alverjones.

Los crianceros que viven en la Tranquita sobreviven gracias a la comercialización del queso, el charqui y la venta de la cabra para ser consumida, debido a estas características la economía de la zona estudiada se característica por actividades de subsistencia, que permiten a las familias conseguir y mantener esta tradición muy común de la IV Región de Coquimbo.

Para realizar las mediciones en terreno, se establecieron cuatro puntos. A continuación se muestra un mapa con los puntos donde se realizaron el trabajo de campo.

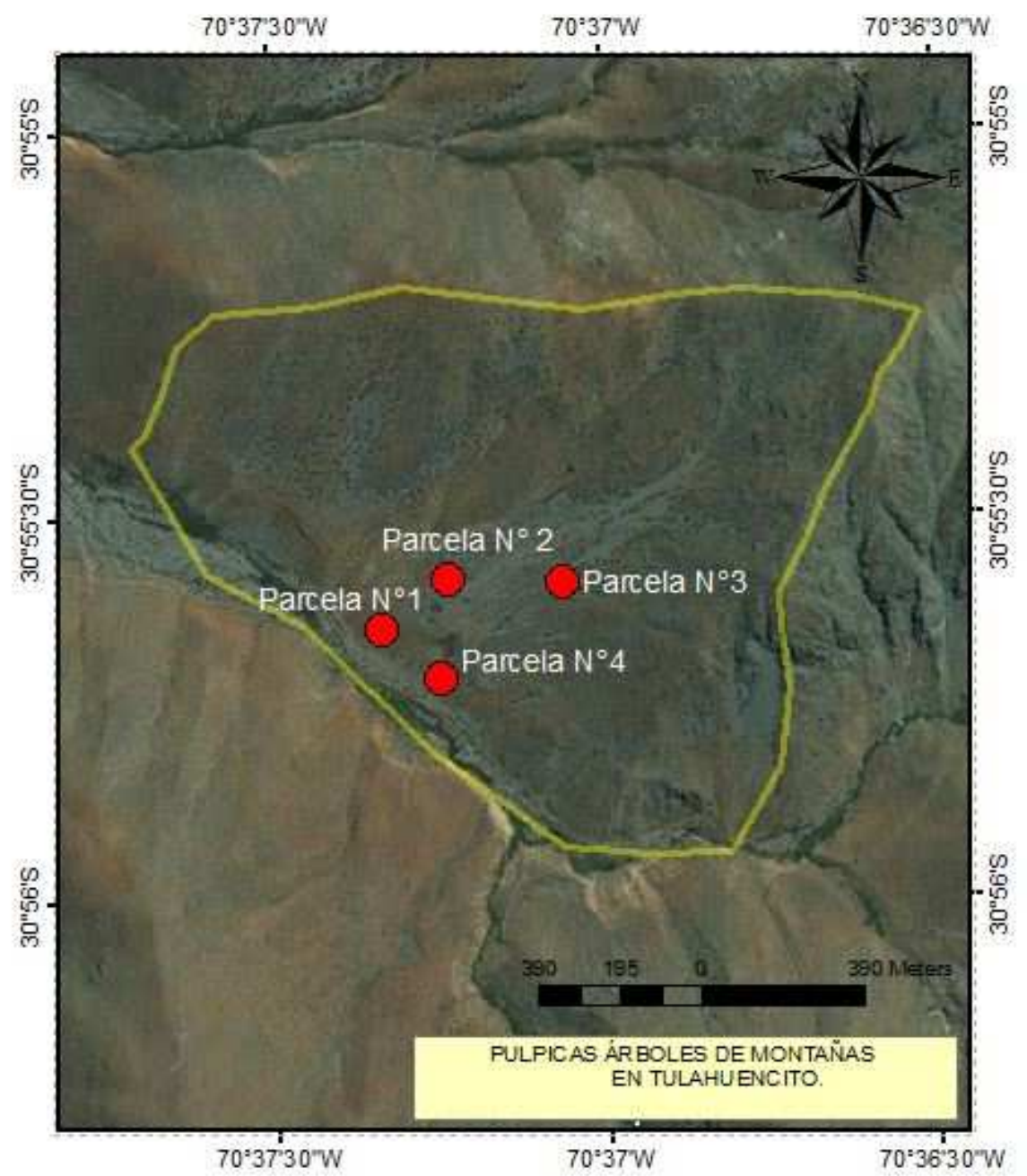

Figura 2: En el mapa los sitios donde se realizaron las mediciones en terreno, en el sector donde se encuentran las pulpicas árboles de montañas, comuna de Monte Patria, Región de Coquimbo.

Publicado en formato digital: Mgtr Eduardo Antonio Jaime Muñoz. ÁRBOLES NATIVOS DE MONTAÑA EN PAISAJES CORDILLERANOS: EL CASO DE LAS PULPICAS DE TULAHUENCITO. Revista Geográfica Digital. IGUNNE. Facultad de Humanidades. UNNE. Año 14. № 27. Enero - Junio 2017. ISSN 1668-5180 Resistencia, Chaco.

En: http://hum.unne.edu.ar/revistas/geoweb/default.htm 
La parcela $N^{\circ} 1$, se ubica en la parte baja de la ladera el pulpical, sector Oeste, en esta zona las plantas se encuentran sobre un canto rodado.

La parcela $\mathrm{N}^{\circ} 2$, se ubica en la parte alta de ladera, lugar donde se concentra la mayor cantidad de pulpicas, sector Oeste

La parcela $N^{\circ} 3$, se localiza sobre los cantos rodados en el sector Este de la ladera.

La parcela $\mathrm{N}^{\circ} 4$, se localiza en la parte baja de la ladera el pulpical, sector Este.

Publicado en formato digital: Mgtr Eduardo Antonio Jaime Muñoz. ÁRBOLES NATIVOS DE MONTAÑA EN PAISAJES CORDILLERANOS: EL CASO DE LAS PULPICAS DE TULAHUENCITO. Revista Geográfica Digital. IGUNNE. Facultad de Humanidades. UNNE. Año 14. № 27. Enero - Junio 2017. ISSN 1668-5180 Resistencia, Chaco.

En: http://hum.unne.edu.ar/revistas/geoweb/default.htm 
Revista Geográfica Digital. IGUNNE. Facultad de Humanidades. UNNE. Año 14. № 27.

Enero - Junio 2017. ISSN 1668-5180 Resistencia, Chaco

\section{RESULTADOS.}

\begin{tabular}{|c|c|c|c|c|c|c|c|}
\hline \multicolumn{8}{|c|}{$\begin{array}{l}\text { Resultados parcela: } N^{\circ} 1 \\
\text { coordenada geográfica: }\left(30^{\circ} 55^{\prime} 30.01^{\prime \prime S} \text { y } 70^{\circ} 37^{\prime} 33.82 " O\right)\end{array}$} \\
\hline Cantidad & Edad & $\begin{array}{l}\text { Alto } \\
\text { (metros) }\end{array}$ & $\begin{array}{l}\text { Ancho } \\
\text { (metros) }\end{array}$ & $\begin{array}{l}\text { Estado } \\
\text { Fenológico }\end{array}$ & Suelo & $\begin{array}{l}\text { Estado de } \\
\text { la planta }\end{array}$ & $\begin{array}{l}\text { Presencia o } \\
\text { ausencia de } \\
\text { plántulas } \\
\text { nuevas }\end{array}$ \\
\hline 1 & Adulto & 3 & 2 & $\begin{array}{l}\text { Hojas verde } \\
\text { claras }\end{array}$ & $\begin{array}{l}\text { Sobre el canto } \\
\text { rodado }\end{array}$ & $\begin{array}{l}\text { Ramas } \\
\text { secas }\end{array}$ & $\begin{array}{l}\text { Ausencia de } \\
\text { plántulas }\end{array}$ \\
\hline 2 & Adulto & 3 & 1 & $\begin{array}{l}\text { Hojas verde } \\
\text { oscuras }\end{array}$ & $\begin{array}{l}\text { Sobre el canto } \\
\text { rodado }\end{array}$ & $\begin{array}{l}\text { Ramas } \\
\text { secas }\end{array}$ & $\begin{array}{l}\text { Ausencia de } \\
\text { plántulas }\end{array}$ \\
\hline 3 & Viejo & 4 & 2 & $\begin{array}{l}\text { Hojas verde } \\
\text { claras }\end{array}$ & $\begin{array}{l}\text { Sobre el canto } \\
\text { rodado }\end{array}$ & $\begin{array}{l}\text { Ramas } \\
\text { secas }\end{array}$ & $\begin{array}{l}\text { Ausencia de } \\
\text { plántulas }\end{array}$ \\
\hline 4 & Viejo & 4 & 1 & $\begin{array}{l}\text { Hojas verde } \\
\text { oscuras }\end{array}$ & $\begin{array}{l}\text { Sobre el canto } \\
\text { rodado }\end{array}$ & $\begin{array}{l}\text { Ramas } \\
\text { secas }\end{array}$ & $\begin{array}{l}\text { Ausencia de } \\
\text { plántulas }\end{array}$ \\
\hline 5 & Adulto & 3 & 2 & $\begin{array}{l}\text { Hojas verde } \\
\text { claras }\end{array}$ & $\begin{array}{l}\text { Sobre el canto } \\
\text { rodado }\end{array}$ & $\begin{array}{l}\text { Ramas } \\
\text { secas }\end{array}$ & $\begin{array}{l}\text { Ausencia de } \\
\text { plántulas }\end{array}$ \\
\hline 6 & Joven & 2 & 2 & $\begin{array}{l}\text { Hojas verde } \\
\text { oscuras }\end{array}$ & $\begin{array}{l}\text { Sobre el canto } \\
\text { rodado }\end{array}$ & $\begin{array}{l}\text { Ramas } \\
\text { secas }\end{array}$ & $\begin{array}{l}\text { Ausencia de } \\
\text { plántulas }\end{array}$ \\
\hline 7 & Adulto & 4 & 3 & $\begin{array}{l}\text { Hojas verde } \\
\text { claras }\end{array}$ & $\begin{array}{l}\text { Sobre el canto } \\
\text { rodado }\end{array}$ & $\begin{array}{l}\text { Ramas } \\
\text { secas }\end{array}$ & $\begin{array}{l}\text { Ausencia de } \\
\text { plántulas }\end{array}$ \\
\hline
\end{tabular}

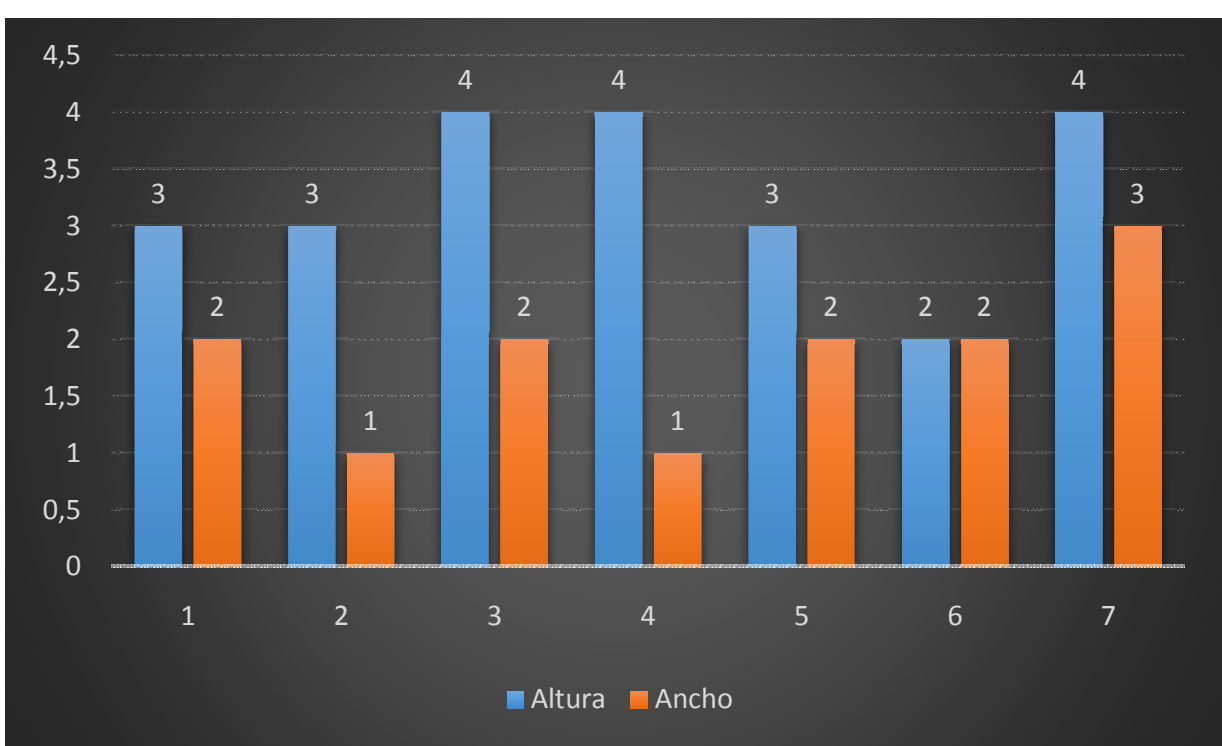

Grafico 1: En el grafico la altura y el ancho de las pulpicas, según las mediciones realizadas en terreno ladera del canto rodado sector Oeste de las poblaciones de los vegetales.

Publicado en formato digital: Mgtr Eduardo Antonio Jaime Muñoz. ÁRBOLES NATIVOS DE MONTAÑA EN PAISAJES CORDILLERANOS: EL CASO DE LAS PULPICAS DE TULAHUENCITO. Revista Geográfica Digital. IGUNNE. Facultad de Humanidades. UNNE. Año 14. № 27. Enero - Junio 2017. ISSN 1668-5180 Resistencia, Chaco.

En: http://hum.unne.edu.ar/revistas/geoweb/default.htm 
Revista Geográfica Digital. IGUNNE. Facultad de Humanidades. UNNE. Año 14. № 27. Enero - Junio 2017. ISSN 1668-5180 Resistencia, Chaco

Resultados parcela: $\mathrm{N}^{\circ} 2$

coordenada geográfica: $\left(30^{\circ} 55^{\prime} 32.97 " S\right.$ y $\left.70^{\circ} 37^{\prime} 22.25 " \mathrm{O}\right)$

\begin{tabular}{||l|l|l|l|l|l|l|l|}
\hline Cantidad & Edad & $\begin{array}{l}\text { Alto } \\
\text { (metros) }\end{array}$ & $\begin{array}{l}\text { Acho } \\
\text { (metros) }\end{array}$ & $\begin{array}{l}\text { Estado } \\
\text { Fenológico }\end{array}$ & Suelo & $\begin{array}{l}\text { Estado de la } \\
\text { planta }\end{array}$ & $\begin{array}{l}\text { Presencia o } \\
\text { ausenciade } \\
\text { plántulas } \\
\text { nuevas }\end{array}$ \\
\hline 1 & $\begin{array}{l}\text { Jove } \\
\mathrm{n}\end{array}$ & 2 & 2 & $\begin{array}{l}\text { Hojas verde } \\
\text { pardas }\end{array}$ & $\begin{array}{l}\text { Suelo con hojas } \\
\text { secas, pisoteado } \\
\text { por vacunos y } \\
\text { animales de carga }\end{array}$ & $\begin{array}{l}\text { Ramas secas y } \\
\text { sin flores. }\end{array}$ & $\begin{array}{l}\text { Ausencia de } \\
\text { plántulas }\end{array}$ \\
\hline 2 & $\begin{array}{l}\text { Jove } \\
\mathrm{n}\end{array}$ & 5 & 3 & $\begin{array}{l}\text { Hojas verde } \\
\text { amarillentas }\end{array}$ & $\begin{array}{l}\text { Suelo con hojas } \\
\text { secas, pisoteado } \\
\text { por vacunos y yas secas y } \\
\text { animales de carga. } \\
\text { sin flores. }\end{array}$ & $\begin{array}{l}\text { Ausencia de } \\
\text { plántulas }\end{array}$ \\
\hline 3 & Viejo & 4 & 5 & $\begin{array}{l}\text { Hojas verde } \\
\text { claras }\end{array}$ & $\begin{array}{l}\text { Suelo con capa } \\
\text { con hojas }\end{array}$ & $\begin{array}{l}\text { Ramas secas y } \\
\text { sin flores. }\end{array}$ & $\begin{array}{l}\text { Ausencia de } \\
\text { plántulas }\end{array}$ \\
\hline 4 & Jove & 3 & 3 & $\begin{array}{l}\text { Hojas verde } \\
\text { oscuras }\end{array}$ & $\begin{array}{l}\text { Suelo con capa de } \\
\text { hojas Ramas secas. }\end{array}$ & $\begin{array}{l}\text { Ausencia de } \\
\text { plántulas }\end{array}$ \\
\hline
\end{tabular}

En: http://hum.unne.edu.ar/revistas/geoweb/default.htm 
Revista Geográfica Digital. IGUNNE. Facultad de Humanidades. UNNE. Año 14. № 27. Enero - Junio 2017. ISSN 1668-5180 Resistencia, Chaco

\begin{tabular}{|l|l|l|l|l|l|l|l|}
\hline 5 & $\begin{array}{l}\text { Jove } \\
\mathrm{n}\end{array}$ & 3 & 2 & $\begin{array}{l}\text { Hojas verde } \\
\text { amarillentas }\end{array}$ & $\begin{array}{l}\text { Suelo con hojas } \\
\text { secas, pisoteado } \\
\text { por vacunos y y } \\
\text { animales de carga. }\end{array}$ & $\begin{array}{l}\text { Ramas secas y } \\
\text { sin flores. }\end{array}$ & $\begin{array}{l}\text { Ausencia de } \\
\text { plántulas }\end{array}$ \\
\hline 6 & Adulo & 5 & 3 & $\begin{array}{l}\text { Hojas verde } \\
\text { claras }\end{array}$ & $\begin{array}{l}\text { Suelo con hojas } \\
\text { secas, pisoteado } \\
\text { por vacunos y } \\
\text { animales de carga. }\end{array}$ & $\begin{array}{l}\text { Ramas secas y } \\
\text { sin flores. }\end{array}$ & $\begin{array}{l}\text { Ausencia de } \\
\text { plántulas }\end{array}$ \\
\hline 7 & $\begin{array}{l}\text { Jove } \\
\mathrm{n}\end{array}$ & 2 & 3 & $\begin{array}{l}\text { Hojas verde } \\
\text { claras }\end{array}$ & $\begin{array}{l}\text { Suelo con hojas } \\
\text { secas, pisoteado samas secas y } \\
\text { por vacunos y y y flores. } \\
\text { animales de carga. }\end{array}$ & $\begin{array}{l}\text { Ausencia de } \\
\text { plántulas }\end{array}$ \\
\hline
\end{tabular}

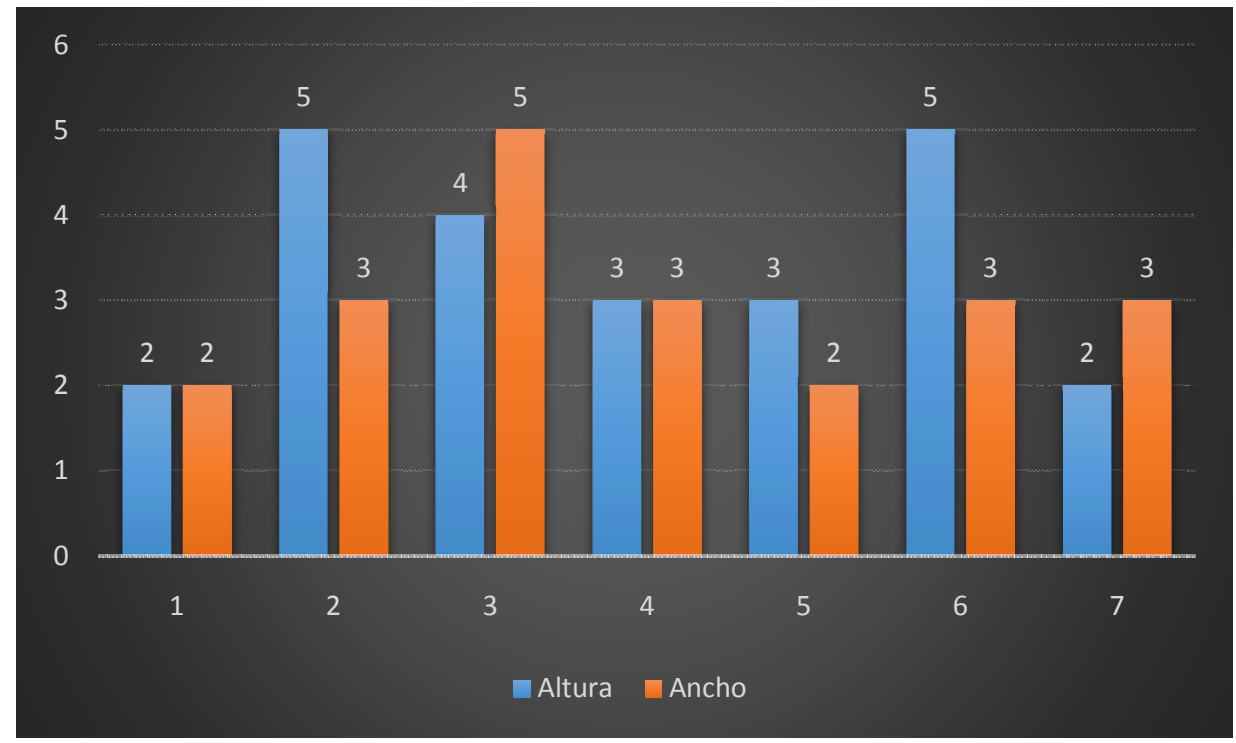

Grafico 2: En el grafico la altura y el ancho de las pulpicas, según las mediciones realizadas en terreno ladera el canto rodado sector Oeste de las poblaciones de los vegetales.

Resultados parcela: $\mathrm{N}^{\circ} 3$

coordenada geográfica: (3055'35.97"S y $70^{\circ} 37^{\prime} 3.51$ "O)

\begin{tabular}{|l|l|l|l|l|l|l|l|}
\hline Cantidad & Edad & $\begin{array}{l}\text { Alto } \\
\text { (metros) }\end{array}$ & $\begin{array}{l}\text { Acho } \\
\text { (metros) }\end{array}$ & $\begin{array}{l}\text { Estado } \\
\text { Fenológico }\end{array}$ & Suelos & $\begin{array}{l}\text { Estado de la } \\
\text { planta }\end{array}$ & $\begin{array}{l}\text { Presencia o } \\
\text { ausencia de } \\
\text { plántulas } \\
\text { nuevas }\end{array}$ \\
\hline 1 & Adulto & 3 & 3 & $\begin{array}{l}\text { Hojas verde } \\
\text { claras. }\end{array}$ & $\begin{array}{l}\text { Suelo } \\
\text { presencia con de } \\
\text { cantos rodados. }\end{array}$ & $\begin{array}{l}\text { Ramas secas y } \\
\text { sin flores }\end{array}$ & $\begin{array}{l}\text { Ausencia de } \\
\text { plántulas }\end{array}$ \\
\hline 2 & Adulto & 4 & 3 & $\begin{array}{l}\text { Hojas verde } \\
\text { amarillentas }\end{array}$ & $\begin{array}{l}\text { Suelo } \\
\text { presencia de den de } \\
\text { cantos rodados } \\
\text { sin flores }\end{array}$ & $\begin{array}{l}\text { Ramas secas y } \\
\text { plántulas de }\end{array}$ \\
\hline 3 & Adulto & 4 & 3 & $\begin{array}{l}\text { Hojas verde } \\
\text { claras }\end{array}$ & $\begin{array}{l}\text { Suelo con capa } \\
\text { con hojas }\end{array}$ & $\begin{array}{l}\text { Ramas secas y } \\
\text { sin flores }\end{array}$ & $\begin{array}{l}\text { Ausencia de } \\
\text { plántulas }\end{array}$ \\
\hline
\end{tabular}

Publicado en formato digital: Mgtr Eduardo Antonio Jaime Muñoz. ÁRBOLES NATIVOS DE MONTAÑA EN PAISAJES CORDILLERANOS: EL CASO DE LAS PULPICAS DE TULAHUENCITO. Revista Geográfica Digital. IGUNNE. Facultad de Humanidades. UNNE. Año 14. № 27. Enero - Junio 2017. ISSN 1668-5180 Resistencia, Chaco.

En: http://hum.unne.edu.ar/revistas/geoweb/default.htm 
Revista Geográfica Digital. IGUNNE. Facultad de Humanidades. UNNE. Año 14. № 27. Enero - Junio 2017. ISSN 1668-5180 Resistencia, Chaco

\begin{tabular}{||l|l|l|l|l|l|l|l|}
\hline 4 & Adulto & 4 & 2 & $\begin{array}{l}\text { Hojas verde } \\
\text { oscuras }\end{array}$ & $\begin{array}{l}\text { Suelo con capa } \\
\text { de hojas }\end{array}$ & Ramas secas & $\begin{array}{l}\text { Ausencia de } \\
\text { plántulas }\end{array}$ \\
\hline 5 & Joven & 3 & 2 & $\begin{array}{l}\text { Hojas verde } \\
\text { amarillentas }\end{array}$ & $\begin{array}{l}\text { Suelo con hojas } \\
\text { secas, posteado } \\
\text { por vacunos y } \\
\text { animales de das flores } \\
\text { carga. }\end{array}$ & $\begin{array}{l}\text { Ramas secas y } \\
\text { sintulas }\end{array}$ \\
\hline 6 & Adulo & 5 & 4 & $\begin{array}{l}\text { Hojas verde } \\
\text { claras }\end{array}$ & $\begin{array}{l}\text { Suelo con hojas } \\
\text { secas, posteado } \\
\text { por vacunos y } \\
\text { animales de din flores } \\
\text { carga. }\end{array}$ & $\begin{array}{l}\text { Ramas secas y } \\
\text { plántulas }\end{array}$ \\
\hline
\end{tabular}

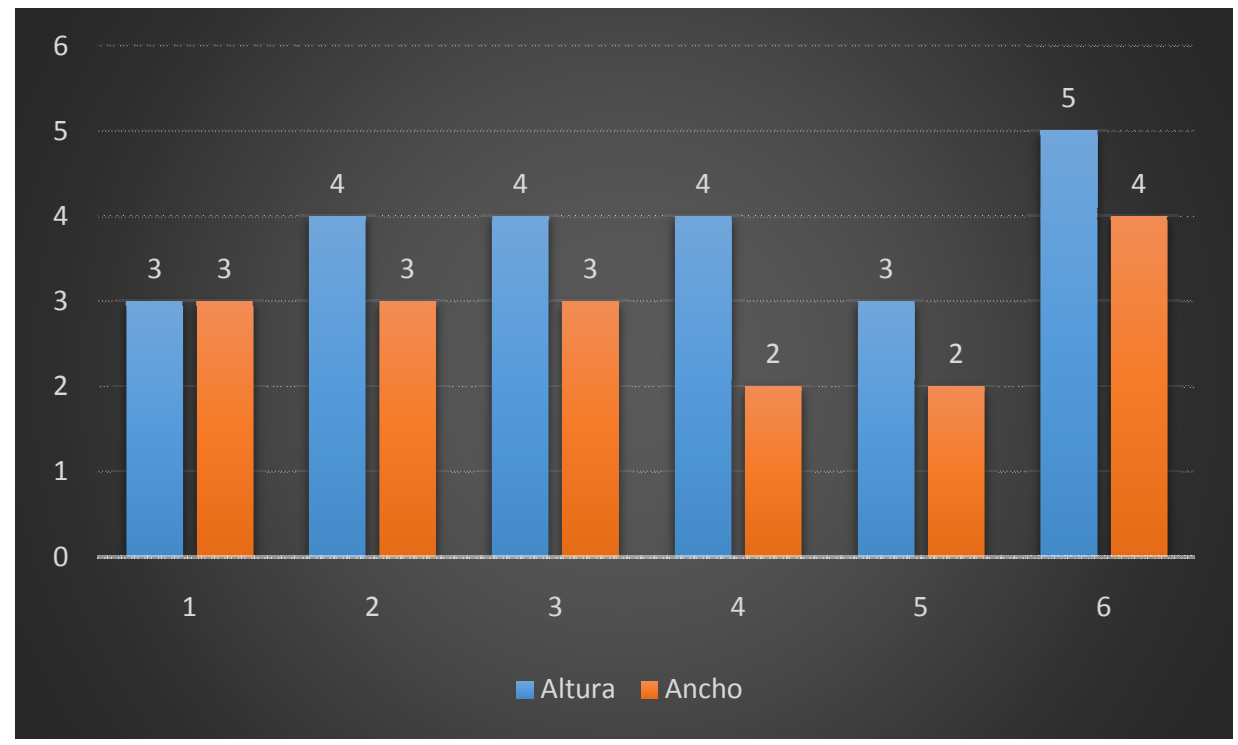

Grafico 3: En el grafico la altura y el ancho de las pulpicas, según las mediciones realizadas en terreno ladera el rodado sector Este de las poblaciones de los vegetales.

Resultados parcela: $\mathrm{N}^{\circ} 4$

coordenada geográfica: $\left(30^{\circ} 55^{\prime} 41.62 " S\right.$ y $\left.70^{\circ} 37^{\prime} 18.10^{\prime \prime}\right)$

\begin{tabular}{|l|l|l|l|l|l|l|l|}
\hline Cantidad & Edad & $\begin{array}{l}\text { Alto } \\
\text { (metros) }\end{array}$ & $\begin{array}{l}\text { Acho } \\
\text { (metros) }\end{array}$ & $\begin{array}{l}\text { Estado } \\
\text { Fenológico }\end{array}$ & $\begin{array}{l}\text { Suelo } \\
\text { planta de la }\end{array}$ & $\begin{array}{l}\text { Presencia } \\
\text { ausencia } \\
\text { plántulas } \\
\text { nuevas }\end{array}$ \\
\hline 1 & Viejo & 3 & 3 & Hojas secas. & $\begin{array}{l}\text { Suelo } \\
\text { presencia de de } \\
\text { cantos rodados. }\end{array}$ & $\begin{array}{l}\text { Ramas secas y } \\
\text { sin flores } \\
\text { plántulas }\end{array}$ \\
\hline 2 & Joven & 2 & 3 & $\begin{array}{l}\text { Hojas verde } \\
\text { amarillentas }\end{array}$ & $\begin{array}{l}\text { Suelo de con } \\
\text { presencia de } \\
\text { cantos rodados }\end{array}$ & $\begin{array}{l}\text { Ramas secas y } \\
\text { sin flores }\end{array}$ & $\begin{array}{l}\text { Ausencia de } \\
\text { plántulas }\end{array}$ \\
\hline
\end{tabular}

Publicado en formato digital: Mgtr Eduardo Antonio Jaime Muñoz. ÁRBOLES NATIVOS DE MONTAÑA EN PAISAJES CORDILLERANOS: EL CASO DE LAS PULPICAS DE TULAHUENCITO. Revista Geográfica Digital. IGUNNE. Facultad de Humanidades. UNNE. Año 14. № 27. Enero - Junio 2017. ISSN 1668-5180 Resistencia, Chaco.

En: http://hum.unne.edu.ar/revistas/geoweb/default.htm 
Revista Geográfica Digital. IGUNNE. Facultad de Humanidades. UNNE. Año 14. № 27. Enero - Junio 2017. ISSN 1668-5180 Resistencia, Chaco

\begin{tabular}{|c|c|c|c|c|c|c|c|}
\hline 3 & Joven & 3 & 2 & $\begin{array}{l}\text { Hojas verde } \\
\text { claras }\end{array}$ & $\begin{array}{lr}\text { Suelo con } \\
\text { presencia de } \\
\text { cantos rodados }\end{array}$ & $\begin{array}{l}\text { Ramas secas y } \\
\text { sin flores }\end{array}$ & $\begin{array}{ll}\text { Ausencia } & \text { de } \\
\text { plántulas } & \end{array}$ \\
\hline 4 & Joven & 5 & 3 & $\begin{array}{ll}\text { Hojas } & \text { verde } \\
\text { pardas } & \end{array}$ & $\begin{array}{lr}\text { Suelo con } \\
\text { presencia de } \\
\text { cantos rodados }\end{array}$ & $\begin{array}{l}\text { Ramas secas y } \\
\text { sin flores }\end{array}$ & $\begin{array}{l}\text { Ausencia de } \\
\text { plántulas }\end{array}$ \\
\hline 5 & Adultos & 3 & 3 & $\begin{array}{l}\text { Hojas verde } \\
\text { amarillentas }\end{array}$ & $\begin{array}{lr}\text { Suelo con } \\
\text { presencia de } \\
\text { cantos rodados }\end{array}$ & $\begin{array}{l}\text { Ramas secas y } \\
\text { sin flores }\end{array}$ & $\begin{array}{l}\text { Ausencia de } \\
\text { plántulas }\end{array}$ \\
\hline 6 & Adulto & 5 & 4 & $\begin{array}{l}\text { Hojas verde } \\
\text { amarillentas }\end{array}$ & $\begin{array}{lr}\text { Suelo con } \\
\text { presencia de } \\
\text { cantos rodados. }\end{array}$ & $\begin{array}{l}\text { Ramas secas y } \\
\text { sin flores }\end{array}$ & $\begin{array}{l}\text { Ausencia de } \\
\text { plántulas }\end{array}$ \\
\hline 7 & Adulto & 5 & 3 & $\begin{array}{l}\text { Hojas } \\
\text { claras }\end{array}$ & $\begin{array}{l}\text { Suelo con } \\
\text { presencia de } \\
\text { cantos rodados }\end{array}$ & $\begin{array}{l}\text { Ramas secas y } \\
\text { sin flores }\end{array}$ & $\begin{array}{l}\text { Ausencia de } \\
\text { plántulas }\end{array}$ \\
\hline
\end{tabular}

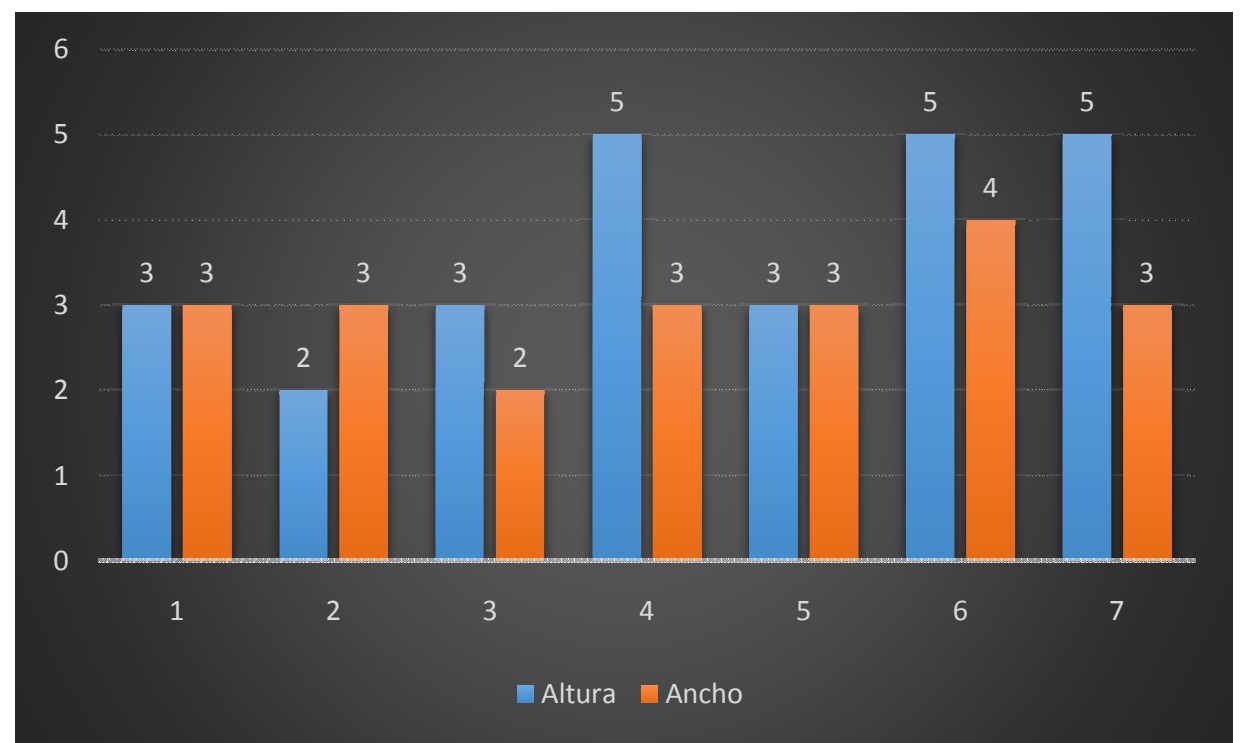

Grafico 4: En el grafico la altura y el ancho de las pulpicas, según las mediciones realizadas en terreno ladera el rodado sector Este de las poblaciones de los vegetales.

\section{DISCUSIÓN Y CONCLUSIONES}

\section{Estado natural de las pulpicas de Tulahuencito.}

El hábitat natural de la pulpica son laderas asoleadas de la precordillera andina, en las provincias centrales de Chile, su floración ocurre en enero y febrero y su fruto es una cápsula estrellada, con 5 lóbulos desiguales (Hoffmann, 1978).

En Tulahuencito las pulpicas están sobre una ladera de exposición Sur, concentrado su población en la parte media y alta de la ladera. Un dato relevante observado en terreno es

Publicado en formato digital: Mgtr Eduardo Antonio Jaime Muñoz. ÁRBOLES NATIVOS DE MONTAÑA EN PAISAJES CORDILLERANOS: EL CASO DE LAS PULPICAS DE TULAHUENCITO. Revista Geográfica Digital. IGUNNE. Facultad de Humanidades. UNNE. Año 14. № 27. Enero - Junio 2017. ISSN 1668-5180 Resistencia, Chaco.

En: http://hum.unne.edu.ar/revistas/geoweb/default.htm 
la ausencia de plantas sobre las laderas de exposición Norte que se encuentran frente al lugar donde crecen estos árboles de montaña.

Este árbol crece desde la Region de Coquimbo (Limari) hasta la Región del Bio-Bio en ambas cordilleras. En la cordillera de la costa es escasa y crece a menor altura. En la de Los Andes se encuentra entre los 1.500 y los 3.000 tanto en quebradas como en faldeos, donde puede llegar a formar pequeños bosquetes puros (Riedemann y Aldunate 2004).

Según los antecedentes planteados en las tablas de registro en la parcela $N^{\circ} 1$ las condiciones naturales del bosque son dispersas encontrándose pocos ejemplares. Una de las causas de esta situación podría ser lo escabroso del suelo donde están las plantas. Esta situación cambia en la parcela $\mathrm{N}^{\circ} 2$, donde las plantas se encuentran sobre una ladera con suelos más concentrados, existen menos piedras en la superficie terrestre y la concentración de las plantas se observa muy claramente, divisando un pequeño bosquete que se ubica en la parte Oeste del área de estudio.

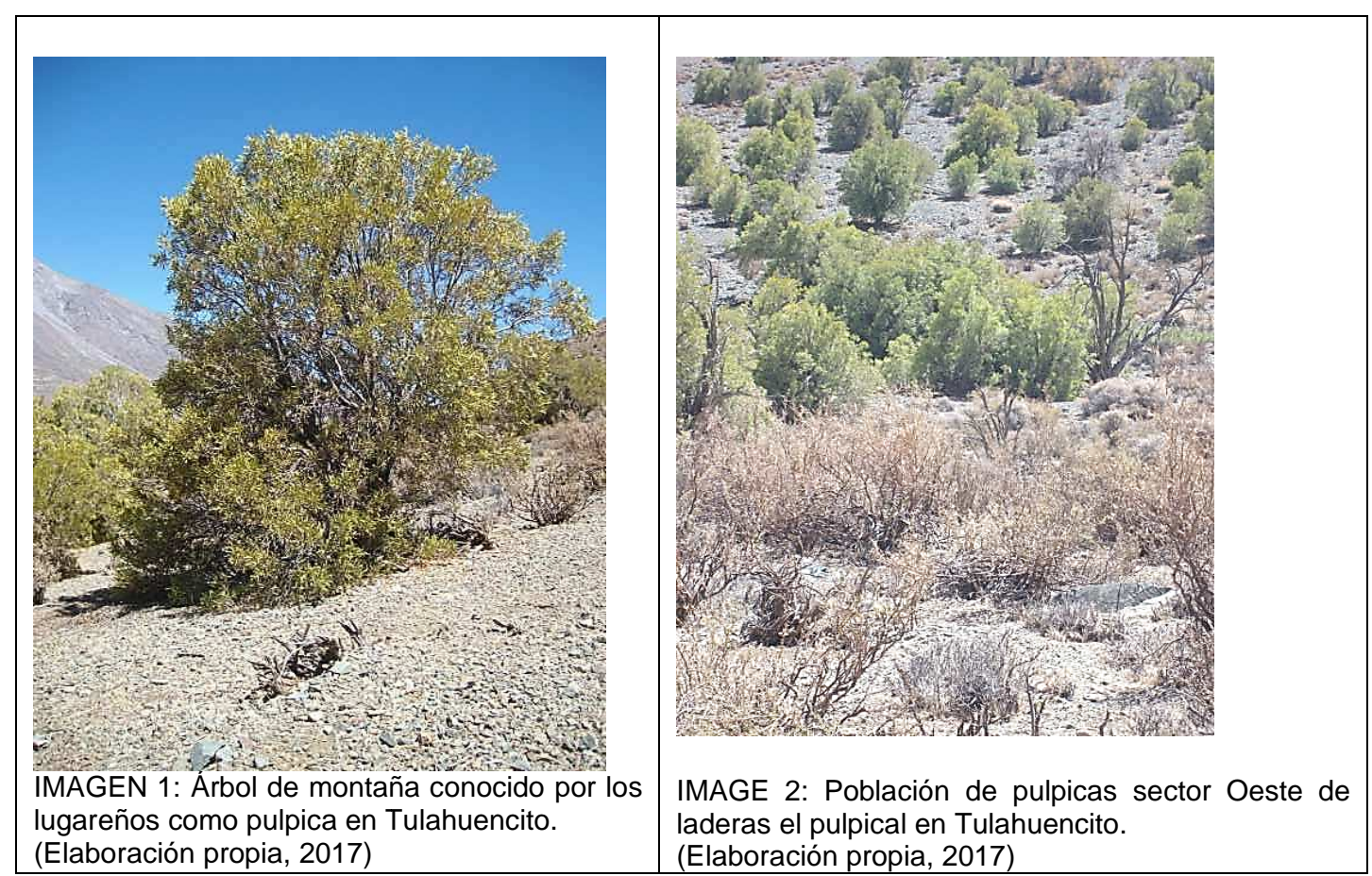

Para (Rodríguez et al 1974).la Kageneckia angustifolia es una de las especies arbóreas que habita los sectores altos cordilleranos Chile, de ahí su importancia de conocer el estado de las poblaciones que existen en el valle del Limari. Las alturas registradas en la parcela $\mathrm{N}^{\circ} 1$ y $\mathrm{N}^{\circ} 2$ evaluadas en la población de pulpicas de Tulahuencito se observan alturas muy significativas en el caso de la parcela $\mathrm{N}^{\circ} 1$ tres plantas registraron 4 metros de alto que fue la mayor altura en el caso del ancho, dos plantas obtuvieron medidas de 2 y 3

Publicado en formato digital: Mgtr Eduardo Antonio Jaime Muñoz. ÁRBOLES NATIVOS DE MONTAÑA EN PAISAJES CORDILLERANOS: EL CASO DE LAS PULPICAS DE TULAHUENCITO. Revista Geográfica Digital. IGUNNE. Facultad de Humanidades. UNNE. Año 14. № 27. Enero - Junio 2017. ISSN 1668-5180 Resistencia, Chaco.

En: http://hum.unne.edu.ar/revistas/geoweb/default.htm 
metros de ancho, a pesar que las plantas son pocas existen ramas secas y partes de las plantas cortadas. La parcela $\mathrm{N}^{\circ} 2$ registra dos alturas máximas de 5 metros. Una planta registró un ancho de 5 metros el árbol es llamativo por lo frondoso de su follaje y lo brillante de sus hojas amarillentas, se localizó en ladera de gran pendiente en la parte baja de acantilado.

Las plantas son el hábitat natural de aves silvestres que se alimentan de los frutos de los vegetales y construyen sus nidos en la copa de los árboles (Hoffmann y Lazo, 2000). Una de las observaciones registradas en la evaluación de la parcela $N^{\circ} 2$ fue el avistamiento de una bandada de tordos que alimentaban sus polluelos un sonido muy característico de su canto llamo la atención los pájaros estaban sobre un árbol de pulpica en el sector Oeste de la ladera. Otro antecedente importante observado en el área de estudio fue el vuelo de una perdiz, ave endémica muy escasa en la zona debido a la caza indiscriminada y la pérdida del hábitat por el monocultivo.

Las mediciones de los cuadrantes $\mathrm{N}^{\circ} 3$ y $\mathrm{N}^{\circ} 4$ realizadas en el sector Este de la ladera dieron a conocer los siguientes resultados. El bosquete se comporta de una forma más dispersa, encontrando árboles en sectores aislados de la ladera, en comparación al cuadrante $\mathrm{N}^{\circ} 2$ donde los arboles eran más concentrados y el sector tiene mayor cantidad de suelo con materia orgánica. En el cuadrante $\mathrm{N}^{\circ} 3$ una planta registró una altura de 5 metros con el ancho de 4 metros sobre el canto rodado que se encontraba cercano el cono del cerro a una altura de 2000 m.s.m.

En el lugar existe una gran pendiente y es más difícil el acceso a los arboles debido a la compleja geografía en la zona, debido el desprendimiento de rocas que se produce al pisar sobre el canto rodado. Según (Riedemann et al, 2008).Las plantas andinas tienen características especiales debido a su adaptación a factores ambientales extremos y cambiantes como son el viento, la nieve, el agua, la sequía, la alta radiación, el corto periodo de tiempo con temperaturas favorables para su desarrollo y los deslizamientos de piedras que le dañan o cortan desde la base.

Estos antecedentes naturales se observan en los arboles de pulpicas existentes en la parcela $\mathrm{N}^{\circ} 3$, de las pulpicas empiezan a disminuir sus altura y las plantas que crecen en los alrededores de los vegetales son más pequeñas y de baja altura, debido a la caída de nieve en tiempos de invierno sobre el paisaje de cubre la ladera el pulpical.

\footnotetext{
Publicado en formato digital: Mgtr Eduardo Antonio Jaime Muñoz. ÁRBOLES NATIVOS DE MONTAÑA EN PAISAJES CORDILLERANOS: EL CASO DE LAS PULPICAS DE TULAHUENCITO. Revista Geográfica Digital. IGUNNE. Facultad de Humanidades. UNNE. Año 14. № 27. Enero - Junio 2017. ISSN 1668-5180 Resistencia, Chaco.

En: http://hum.unne.edu.ar/revistas/geoweb/default.htm
} 
A continuación se presenta algunas fotografías del sector Este de la ladera, donde se visualizan las pulpicas.

\begin{tabular}{|c|c|}
\hline 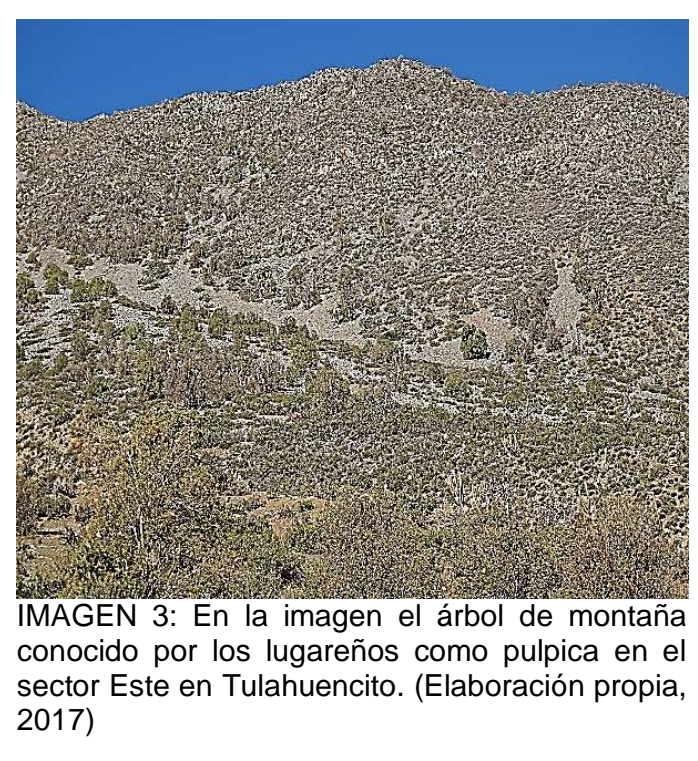 & $\begin{array}{l}\text { IMAGEN 4: En la imagen una población de pulpicas } \\
\text { IMÁn } \\
\text { sector Este de laderas el pulpical en Tulahuencito. } \\
\text { (Elaboración propia, 2017) }\end{array}$ \\
\hline
\end{tabular}

\section{Efectos de las actividades extractivas humanas sobre el paisaje que cubre las pulpicas arboles de montaña en Tulahuencito.}

En el último tiempo las actividades extractivas humanas han avanzado hacia zonas vulnerables, este desarrollo ha puesto en riesgo la vegetación propia de ecosistemas semiáridos en el norte chico.

La degradación de la vegetación nativa producto de la actividad ganadera, minera y agrícola ha llevado a la destrucción de los hábitat naturales de muchas especies locales (Jaime y Villaseñor, 2016).

Según los datos dados a conocer en las tablas de resultados de las parcelas $N^{\circ} 1, N^{\circ} 2$, $\mathrm{N}^{\circ} 3$ y $\mathrm{N}^{\circ} 4$ el suelo presente en la unidad de estudio, se encontraba pisoteado producto de la actividad ganadera muy común en Tulahuencito. El paso de la cabra sobre la capa de hojas que cubre las raíces de los arboles provoca el desprendimiento de la capa de hojas que cubre las raíces de los árboles y por efecto del terreno la erosión del suelo.

Esta problemática ambiental sumada a los años secos, ha sido unas de las causas de la escasa germinación de las semillas que no han conseguido sobrevivir debido a los

\footnotetext{
Publicado en formato digital: Mgtr Eduardo Antonio Jaime Muñoz. ÁRBOLES NATIVOS DE MONTAÑA EN PAISAJES CORDILLERANOS: EL CASO DE LAS PULPICAS DE TULAHUENCITO. Revista Geográfica Digital. IGUNNE. Facultad de Humanidades. UNNE. Año 14. № 27. Enero - Junio 2017. ISSN 1668-5180 Resistencia, Chaco.

En: http://hum.unne.edu.ar/revistas/geoweb/default.htm
} 
Revista Geográfica Digital. IGUNNE. Facultad de Humanidades. UNNE. Año 14. № 27.

Enero - Junio 2017. ISSN 1668-5180 Resistencia, Chaco

efectos de la actividad ganadera sobre la superficie que cubre el bosquete de pulpicas.

Monte Patria es la comuna de la que proviene la mayoría de los pastores trashumantes que en la actualidad lleva su ganado a los valles calingastinos, en San Juan Argentina (GORE, 2014).

Los cabreros en la zona, desarrollan procesos de trashumancia en otoño e invierno se encuentran pastando sus cabras en el bosquete de pulpicas y en la estación de verano y primavera ellos van con sus cabras a la alta cordillera. Dentro de los hallazgos realizados en terreno en la parcela $N^{\circ} 4$, se encontraba una majada de cabreros de zona quienes se ubicaron es la parte baja de la ladera.

El sobrepastoreo es la explotación más allá de lo que puede soportar una vega andina y su peor efecto tiene que ver con bajar la productividad, haciendo que se pierdan especies. Cuando el pastoreo es realizado por el ganado caprino, las cabras se alimentan en vegas y laderas, lo que además de los efectos antes mencionado trae consigo la modificación de las dominancias, pues las especies que no se comen son las que empiezan a aumentar (Squeo, 2015).

Junto a la población de pulpicas de Tulahuencito, crecen especies de gran interés para el ganado caprino como el guayacán (Porlieria chilensis I.M.Johnst) especie endémica del Limarí, rumpiato: (Bridgesia incisifolia Bert. ex Cambess), sandillones: (Eriosyce aurata (Pfeiff.) Backeb) y granadilla: (Mutisia spectabilis Phil).estas plantas son consumidas por las cabras.

\section{Estrategias de conservación de las pulpicas de Tulahuencito en el tiempo}

Uno de los antecedentes que adquiriere gran relevancia en la evaluación de la población de pulpicas es la no presencia de nuevas plántulas en el área de estudio situación que ha llamado la atención dentro de la comunidad, siendo necesaria la recuperación de nuevas especies con el tiempo.

El primer paso para recuperar estos árboles nativos de montaña es descubrir nuevas técnicas de propagación con la ayuda del conocimiento popular de la comunidad. En este sentido se recomienda la colecta de semillas en el sitio mismo donde se encuentran las plantas. La idea es poder encontrar métodos de propagación para que los cabreros y la comunidad del sector pueda ayudar a recuperar la especie nativa.

\footnotetext{
Publicado en formato digital: Mgtr Eduardo Antonio Jaime Muñoz. ÁRBOLES NATIVOS DE MONTAÑA EN PAISAJES CORDILLERANOS: EL CASO DE LAS PULPICAS DE TULAHUENCITO. Revista Geográfica Digital. IGUNNE. Facultad de Humanidades. UNNE. Año 14. № 27. Enero - Junio 2017. ISSN 1668-5180 Resistencia, Chaco.

En: http://hum.unne.edu.ar/revistas/geoweb/default.htm
} 


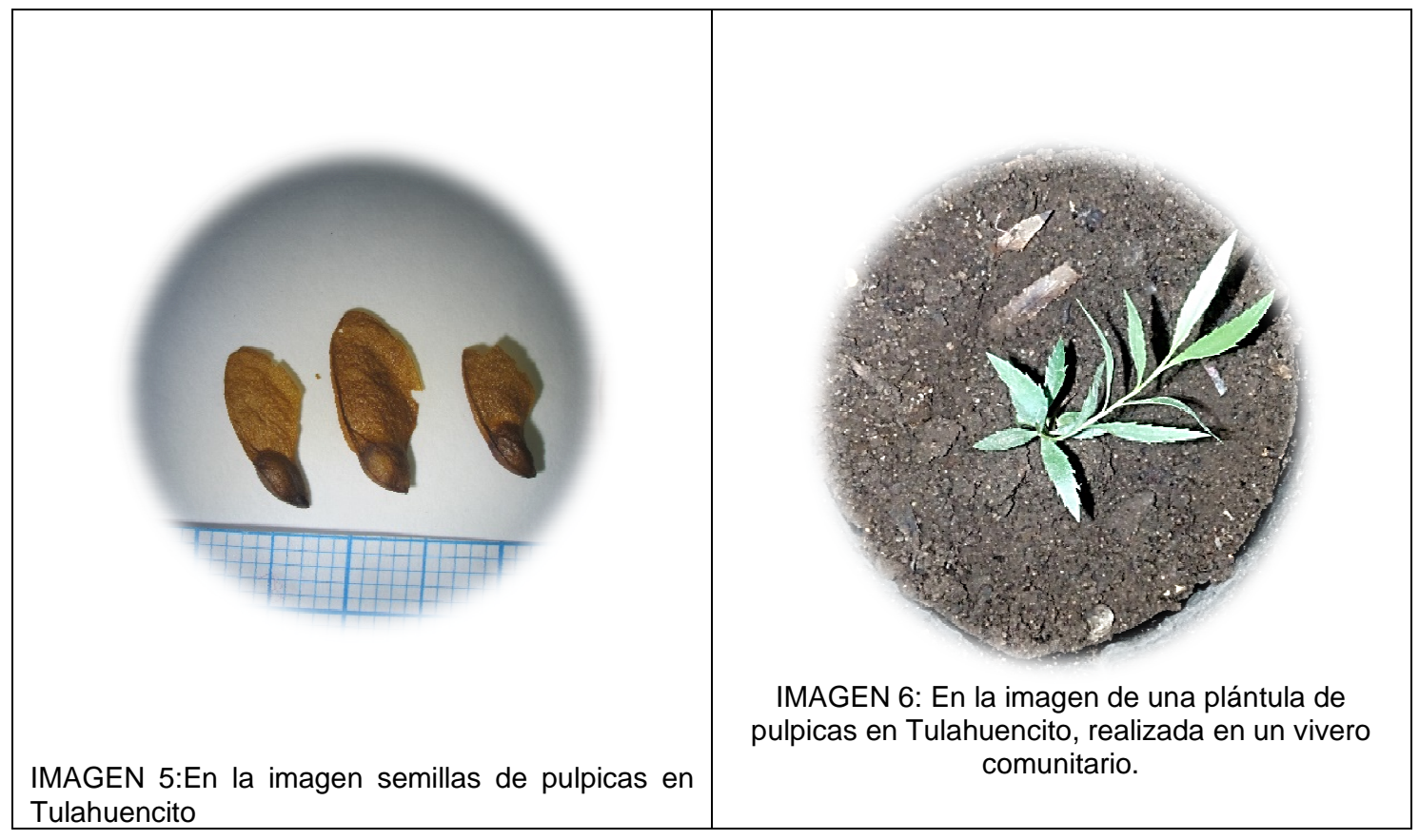

Otra idea a desarrollar en el territorio es continuar el trabajo de educación ambiental que se está realizando con la escuela de la zona. En este sentido esta estrategia educativa puede ayudar a mejorar la enseñanza de los niños en contextos rurales ayudando a mejorar sus resultados (Diaz, et al, 2016).

Los niños y niñas de la comunidad de La Tranquita son los futuros guardianes de las pulpicas. Por esta razón es necesario y formar conciencia en el cuidado y protección de la biodiversidad presente en el territorio, acercando a la comunidad a las problemáticas ambientales para que las personas puedan tomar responsablemente decisiones para enfrentar el desarrollo en estas zonas aportadas.

El conocimiento que se da a partir de este estudio, permitirá también desarrollar un turismo educativo sustentable, donde la población de La Tranquita, pueda ofrecer senderos turísticos educativos a las personas que se interesen por aprender de estos árboles de montaña, de sus características naturales y los métodos de propagación que existen.

Los pequeños productores locales dedicados al comercio del queso de cabra, el charqui, la carne de cabro y la venta de frutos secos puedan aprovechar esta instancia para poder vender sus productos, promoviendo una economía sustentable dentro del territorio.

Publicado en formato digital: Mgtr Eduardo Antonio Jaime Muñoz. ÁRBOLES NATIVOS DE MONTAÑA EN PAISAJES CORDILLERANOS: EL CASO DE LAS PULPICAS DE TULAHUENCITO. Revista Geográfica Digital. IGUNNE. Facultad de Humanidades. UNNE. Año 14. № 27. Enero - Junio 2017. ISSN 1668-5180 Resistencia, Chaco.

En: http://hum.unne.edu.ar/revistas/geoweb/default.htm 
Revista Geográfica Digital. IGUNNE. Facultad de Humanidades. UNNE. Año 14. № 27.

Enero - Junio 2017. ISSN 1668-5180 Resistencia, Chaco

\section{BIBLIOGRAFIA.}

DIARIO OVALLE HOY. 2017. Queso de cabra sellado el vino tinto: el novedoso producto de un criancero de la región. En http://ovallehoy.cl/queso-de-cabra-sellado-alvino-tinto-el-novedoso-producto-de-un-criancero-de-la-region/

DIAZ. R., OSSES. S y MUÑOZ, S., Factores e interacciones del proceso enseñanzaaprendizaje en contextos rurales de la Araucanía Chile. Revista Estudios Pedagógicos XLII, No 3: 111-128.

GORE, 2014. Trashumantes de la cordillera de Los Andes. Los últimos pastores del hemisferio sur. Corporación Paso Agua Negra y Gobierno Regional de Coquimbo.

hace que se pierdan especies (vegetales) y cambien las dominancias».

HOFFMANN, A. 2004. Cactáceas en la flora silvestre de Chile. Ediciones Fundación Claudio Gay. Santiago, Chile.

HOFFMANN, A. 2012. Flora silvestre de Chile, zona central. (5 $5^{\text {ta }}$ edición). Fundación Claudio Gay. Santiago de Chile.

HOFFMANN, A. C. FARGA, J. LASTRA, \& E. VEGHAZI. 2003. Plantas medicinales de uso común en Chile. Fundación Claudio Gay. Santiago. Chile.

HOFFMANN, A., J. WATSON \& A. FLORES. 2015. Flora silvestre de Chile, Cuando el desierto florece, Volumen 1, Monocotiledóneas y otros taxones. Fundación Claudio Gay. Santiago, Chile.

HOFFMANN, A., M. KALIN, F. LIBERONA, M. MUÑOZ \& J. WATSON. 1998. Plantas altoandinas en la flora silvestre de Chile. Santiago, Chile. Fundación Claudio Gay. Santiago, Chile.

JAIME, E \& R. VILLASEÑOR 2016. Flora nativa de interés apícola, en la cuenca de Tulahuencito, Región de Coquimbo, (Chile). Anales del Museo de Historia Natural de Valparaíso. .

JAIME, E \& R. VILLASEÑOR 2016. Trepadoras y parasitas en el cerro La Olla, un estudio etnobotanico en la comuna de Monte Patria, Región de Coquimbo, Chile: Chloris Chilensis Año 19. N 1. URL: www.chlorischile.cl

JAIME, E. 2013. Conservación de una población vegetal de Kageneckia angustifolia: Pulpica en el sector de Tulahuencito, comuna de Monte Patria, Región de Coquimbo. Revista Simiente 83 (1-4): 1-105.

JAIME, E. 2014. Hacia prácticas comunitarias que promuevan la conservación del medio ambiente y mejoren la calidad de vida de las comunidades rurales: El caso de los cabreros de Tulahuencito, comuna de Monte Patria, Región de Coquimbo. Tesis de grado, programa de magister en Desarrollo Regional y Medio Ambiente, Universidad de Valparaíso.

\footnotetext{
Publicado en formato digital: Mgtr Eduardo Antonio Jaime Muñoz. ÁRBOLES NATIVOS DE MONTAÑA EN PAISAJES CORDILLERANOS: EL CASO DE LAS PULPICAS DE TULAHUENCITO. Revista Geográfica Digital. IGUNNE. Facultad de Humanidades. UNNE. Año 14. № 27. Enero - Junio 2017. ISSN 1668-5180 Resistencia, Chaco.

En: http://hum.unne.edu.ar/revistas/geoweb/default.htm
} 
JORQUERA, A., C. ITURRIETA, F. SÁNCHEZ, M. VALDÉS, M. ESPINOSA \& S. ESPINOSA. 2013. La importancia de los humedales del río Mostazal, comuna de Monte Patria. Junta vigilancia del río Mostazal y sus afluentes, Proyecto Fondo de Protección Ambiental FPA 4-G-011-2012 El valle en nuestras manos: Junto protegiendo la biodiversidad de los humedales que mantienen nuestra vida y cultura. Chile.

RIEDEMANN, P. \& G. ALDUNATE. 2003. Flora nativa de valor ornamental, identificación y propagación. Zona Central. Editorial Andrés Bello. Santiago, Chile.

RIEDEMANN, P., G. ALDUNATE \& S. TEILLIER. 2008. Flora nativa de valor ornamental, identificación y propagación, cordillera de los Andes. Editorial Andrés Bello. Santiago, Chile.

RODRIGUEZ, R., O. MATTHEI, O. \& M. QUEZADA. 1983. Flora arbórea de Chile. Editorial de la Universidad de Concepción. Chile.

SÁNCHEZ, A. \& R. MORALES. 1993. Las regiones de Chile, espacio físico y humanoeconómico. Editorial Universitaria. Santiago, Chile.

SQUEO, F., (2015). Seminario tiempo, economía y desarrollo en la Región de Coquimbo. Francisco A. Squeo sobre impacto de las veranadas: «Un sobrepastoreo hace que se pierdan especies (vegetales) y cambien las dominancias».

SQUEO, F., G. ARANCIO \& J. GUTIERREZ. 2001. Libro rojo de la flora nativa y los sitios prioritarios para su conservación en la Región de Coquimbo.Ediciones Universidad de La Serena. La Serena. Chile.

SQUEO, F., R.OSORIO \& G. ARANCIO. 1994. Flora de los Andes de Coquimbo: cordillera de Doña Ana. Ediciones Universidad de La Serena. La Serena. Chile.

Publicado en formato digital: Mgtr Eduardo Antonio Jaime Muñoz. ÁRBOLES NATIVOS DE MONTAÑA EN PAISAJES CORDILLERANOS: EL CASO DE LAS PULPICAS DE TULAHUENCITO. Revista Geográfica Digital. IGUNNE. Facultad de Humanidades. UNNE. Año 14. № 27. Enero - Junio 2017. ISSN 1668-5180 Resistencia, Chaco.

En: http://hum.unne.edu.ar/revistas/geoweb/default.htm 